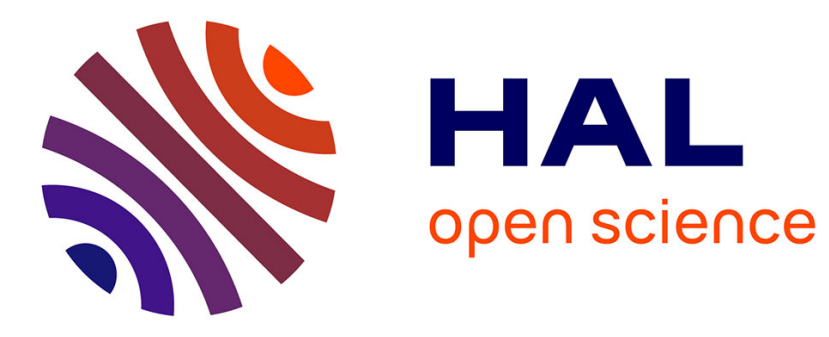

\title{
Studies of cyclodextrin complexes by positron annihilation
}

\author{
F. Hsu, J. Michael, L. Song, D. Armstrong
}

\section{To cite this version:}

F. Hsu, J. Michael, L. Song, D. Armstrong. Studies of cyclodextrin complexes by positron annihilation. Journal de Physique IV Proceedings, 1993, 03 (C4), pp.C4-297-C4-303. 10.1051/jp4:1993448 . jpa00251491

\section{HAL Id: jpa-00251491 https://hal.science/jpa-00251491}

Submitted on 1 Jan 1993

HAL is a multi-disciplinary open access archive for the deposit and dissemination of scientific research documents, whether they are published or not. The documents may come from teaching and research institutions in France or abroad, or from public or private research centers.
L'archive ouverte pluridisciplinaire HAL, est destinée au dépôt et à la diffusion de documents scientifiques de niveau recherche, publiés ou non, émanant des établissements d'enseignement et de recherche français ou étrangers, des laboratoires publics ou privés. 


\title{
Studies of cyclodextrin complexes by positron annihilation
}

\author{
F.H. HSU, J.M. MICHAEL, L. SONG and D.W. ARMSTRONG* \\ Department of Physics and Astronomy, Georgia State University, Atlanta, GA 30033, U.S.A. \\ * Department of Chemistry, University of Missouri-Rolla, Rolla, MO 65401, U.S.A.
}

\begin{abstract}
The positron annihilation technique has been applied to study cyclodextrin complexes formation. Lifetime spectra have been measured in aqueous solutions of nitrophenol isomers, cyclodextrins, and cyclodextrins mixed with nitrophenol isomers. The spectra were resolved into three lifetime components. The intensity, $I_{3}$, of the longest-lived component was found to be decreased linearly with respect to the concentration of nitrophenol isomers in an aqueous solution. In the aqueous solution of cyclodextrins, concentration had little effect on $\mathrm{I}_{3}$. However, $\mathrm{I}_{3}$ increased with respect to the concentration of cyclodextrins in aqueous solutions mixed with a fixed amount of nitrophenol isomers. Several methods based on these findings are proposed to determine the formation equilibrium constants for inclusion complexes of nitrophenols by cyclodextrins.
\end{abstract}

\section{Introduction}

The goal of the present research was to apply positron annihilation lifetime measurements to the study of inclusion compounds, cyclodextrins. Inclusion compounds are substances which may play "host" to other chemical species ("guests")/1/. These host compounds have a structure which allows the guest molecule to be carried in the host molecule. The present work studied the effect of cyclodextrins on positron lifetime spectra in an aqueous solution with nitrophenol isomers. Several methods are proposed to determine the equilibrium constants of nitrophenol isomers with cyclodextrins.

Nitrophenols (NPH) are diamagnetic compounds which are known to be good electron acceptors. They are good inhibitors of positronium (Ps) formation. On the basis of the spur reaction model of Ps formation, the good inhibition effects of these molecules can be accounted for by their high reactivity toward solvated electrons.

Cyclodextrins (CD) are composed of $\alpha$-(1,4)-linkages of a number of glucose units. They are given a Greek letter designation to identify the number of glucose units. $\alpha$-, $\beta$ - and $\gamma$-cyclodextrin have 6,7 , and 8 units respectively. The most important characteristic of cyclodextrins is their ability to form inclusion complexes in which the guest compounds are included in the cavity. These guest compounds range from polar acids to highly apolar aromatic hydrocarbons. The inclusion complexes may be formed in solution or in the crystalline state. The molar ratio of the host molecule to the guest molecule is usually $1: 1$ for complexes formed in solution. 


\section{Inclusion Phenomena and Positron Annihilation Techniques}

Materials which normally react with electrons, positrons, or ortho-Ps will lose most of their reactivities when they are in a complexed form. The difference in reactivities between the complexed and uncomplexed states make it possible to determine the equilibrium constants of the systems. Jean and Ache resolved positron lifetime spectra into two lifetime components in their study of inclusion complexes formation by the positron annihilation technique/2\%. Their study correlated changes in the annihilation rate of the second lifetime component with changes in cyclodextrin concentration in the presence of a constant nitrophenol concentration.

Resolution of the lifetime spectra into three lifetime components may require a different interpretation. If a lifetime spectrum consists of three lifetime components, a two-lifetime fit of the spectrum may force changes in intensities of the second and third components to appear as changes in both the lifetime and intensity of the second component. It is therefore very difficult to compare results from the annihilation rate of the second component of a two-lifetime fit to that from the annihilation rate of the third component of a three-lifetime fit.

In the present study, lifetime spectra were resolved into three lifetime components. Definite changes were seen in both the intensity and annihilation rate of the third lifetime component. However, changes in the intensity of the third component were more profound. Therefore we have chosen to use the intensity to determine the equilibrium constants. Another reason is that the interpretation of the intensity of the third component is well defined, that is, due to pick-off annihilation of ortho-Ps.

\section{Determination of equilibrium constants from positron annihilation data}

The association of the cyclodextrin and guest molecules may be described by the reaction:

$$
\mathrm{C}+\mathrm{G} \underset{\mathrm{K}_{\mathrm{C}}}{\stackrel{5}{\leftrightarrows}} \mathrm{CG} \text {, }
$$

where $\mathrm{C}$ is the cyclodextrin molecule and $\mathrm{G}$ is the guest molecule. The equilibrium constant $\mathrm{K}_{\mathrm{C}}$ is:

$$
\mathrm{K}_{\mathrm{C}}=\frac{[\mathrm{CG}]}{([\mathrm{C}]-[\mathrm{CG}])([\mathrm{G}]-[\mathrm{CG}])},
$$

where [C], [G], and [CG] are concentrations of the cyclodextrin, the guest molecule, and the complex, respectively; [C]-[CG] and [G]-[CG] denote the portion of the cyclodextrin and the guest molecule in solution that are not complexed. To determine $\mathrm{K}_{\mathrm{C}}$ from positron annihilation data, the following methods are proposed:

(1) When [G] is larger than [C], then [CG] is much less than [G]. $K_{C}$ can be approximated as:

then

$$
\mathrm{K}_{\mathrm{C}}=\frac{[\mathrm{CG}]}{([\mathrm{C}]-[\mathrm{CG}])[\mathrm{G}]}
$$

$$
[\mathrm{CG}]=\frac{\mathrm{K}_{\mathrm{C}}[\mathrm{C}][\mathrm{G}]}{1+\mathrm{K}_{\mathrm{C}}[\mathrm{G}]} \text {. }
$$

If the intensity, $I_{3}$, of the third lifetime component is a linear function of the concentration of the cyclodextrin, the guest molecule and the complex, then

$$
\mathrm{I}_{3} \mathrm{C}=\mathrm{I}_{3}{ }^{\mathrm{o}}-\mu_{\mathrm{C}}[\mathrm{C}]
$$




$$
\begin{aligned}
& \mathbf{I}_{3}{ }^{\mathrm{C}}=\mathrm{I}_{3}{ }^{\circ}-\mu_{\mathrm{G}}[\mathrm{G}] \text {, and } \\
& \mathrm{I}_{3}{ }^{\mathrm{CG}}=\mathrm{I}_{3}{ }^{\mathrm{O}}-\mu_{\mathrm{C}}([\mathrm{C}]-[\mathrm{CG}])-\mu_{\mathrm{G}}([\mathrm{G}]-[\mathrm{CG}])-\mu_{\mathrm{CG}}[\mathrm{CG}] .
\end{aligned}
$$

Where $\mathrm{I}_{3}^{\mathrm{C}}, \mathrm{I}_{3}{ }^{\mathrm{C}}, \mathrm{I}_{3}{ }^{\mathrm{CG}}$ and $\mu_{\mathrm{C}}, \mu_{\mathrm{G}}, \mu_{\mathrm{CG}}$ are the intensities of the third lifetime component and inhibition constants of the cyclodextrin, the guest molecule, and the complex, respectively. $\mathrm{I}_{3}{ }^{\circ}$ is the intensity of the third lifetime component in the solvent alone. By substituting [CG] in the equation for $\mathrm{I}_{3}^{\mathrm{CG}}$ which can be written as:

$$
\mathrm{I}_{3}{ }^{\mathrm{CO}}=\mathrm{I}_{3}{ }^{\circ}-\mu_{\mathrm{C}}[\mathrm{C}]-\mu_{\mathrm{G}}[\mathrm{G}]+\left(-\mu_{\mathrm{CG}}+\mu_{\mathrm{C}}+\mu_{\mathrm{G}}\right) \frac{\mathrm{K}_{\mathrm{C}}[\mathrm{C}][\mathrm{G}]}{1+\mathrm{K}_{\mathrm{C}}[\mathrm{G}]} .
$$

The right side can be simplified by letting

$$
\begin{aligned}
& \mathrm{b}=\mathrm{I}_{3}{ }^{\circ}-\mu_{\mathrm{G}}[\mathrm{G}] \text { and } \\
& \mu_{\mathrm{o}}=-\mu_{\mathrm{CG}}+\mu_{\mathrm{C}}+\mu_{\mathrm{G}} ;
\end{aligned}
$$

and after factoring out $[\mathrm{C}]$, then

$$
\mathrm{I}_{3}^{\mathrm{CG}}=\mathrm{b}+\left(-\mu_{\mathrm{C}}+\mu_{\mathrm{o}} \frac{\mathrm{K}_{\mathrm{C}}[\mathrm{G}]}{1+\mathrm{K}_{\mathrm{C}}[\mathrm{G}]}\right)[\mathrm{C}] .
$$

If we plot $\mathrm{I}_{3}{ }^{\mathrm{CO}}$ verses $[\mathrm{C}]$, then the slope $\mathrm{m}$ is:

$$
\mathrm{m}=-\mu_{\mathrm{C}}+\mu_{\mathrm{o}} \frac{\mathrm{K}_{\mathrm{C}}[\mathrm{G}]}{1+\mathrm{K}_{\mathrm{C}}[\mathrm{G}]} .
$$

By measuring slopes for two concentrations of $[G]_{1}$ and $[G]_{2}, K_{C}$ can be solved as follows:

$$
\mathrm{K}_{\mathrm{C}}=\frac{\left(\mathrm{m}_{1}+\mu_{\mathrm{C}}\right) /[\mathrm{G}]_{1}-\left(\mathrm{m}_{2}+\mu_{\mathrm{C}}\right) /[\mathrm{G}]_{2}}{\mathrm{~m}_{2}-\mathrm{m}_{1}} .
$$

(2) It is reasonable to assume that $\mu_{\mathrm{CG}}<<\mu_{\mathrm{G}}$, then the above expression for $\mathrm{m}$ can be simplified by using

then

$$
\mu_{\mathrm{o}}=-\mu_{\mathrm{CO}}+\mu_{\mathrm{C}}+\mu_{\mathrm{G}} \approx \mu_{\mathrm{C}}+\mu_{\mathrm{G}}
$$

$$
\mathrm{m} \approx-\mu_{\mathrm{C}}+\left(\mu_{\mathrm{C}}+\mu_{\mathrm{G}}\right) \frac{\mathrm{K}_{\mathrm{C}}[\mathrm{G}]}{1+\mathrm{K}_{\mathrm{C}}[\mathrm{G}]} .
$$

Solving for $\mathrm{K}_{\mathrm{C}}$ which can be expressed as follows:

$$
\mathbf{K}_{\mathrm{C}}=\frac{\left(\mathrm{m}+\mu_{\mathrm{C}}\right)}{\left(\mu_{\mathrm{G}}-\mathrm{m}\right)[\mathrm{G}]} \text {. }
$$

The intensity $\mathrm{I}_{3}$ for the aqueous solution of nitrophenol isomers and cyclodextrins was a very linear function of concentration. In addition, the intensity $\mathrm{I}_{3}$ for the mixed aqueous solution containing cyclodextrins and a constant concentration of nitrophenol isomers was very linear in the low concentration region of cyclodextrins. Therefore, both methods should render a good evaluation of $K_{C}$ using the low cyclodextrin concentration region. Obviously, a problem exists for method (1) when $m_{1}$ and $m_{2}$ are very close, in which case this procedure will give a very large error.

(3) When $[C]$ is larger than $[G]$, then $[C G]$ is much less than $[C]$. ( $[C G]$ is less than $[C]$ even for $[\mathrm{C}] \approx[\mathrm{G}])$. $\mathrm{K}_{\mathrm{C}}$ can be approximated as:

$$
\mathrm{K}_{\mathrm{C}}=\frac{[\mathrm{CG}]}{[\mathrm{C}]([\mathrm{G}]-[\mathrm{CG}])}
$$

then

$$
[\mathrm{CG}]=\frac{\mathrm{K}_{\mathrm{C}}[\mathrm{C}][\mathrm{G}]}{1+\mathrm{K}_{\mathrm{C}}[\mathrm{C}]},
$$


and

$$
\mathrm{I}_{3}{ }^{\mathrm{CG}}=\mathrm{I}_{3}{ }^{\circ}-\mu_{\mathrm{C}}[\mathrm{C}]-\mu_{\mathrm{G}}[\mathrm{G}]+\mu_{\circ} \frac{\mathrm{K}_{\mathrm{C}}[\mathrm{C}][\mathrm{G}]}{1+\mathrm{K}_{\mathrm{C}}[\mathrm{C}]} \text {. }
$$

Let $\mathrm{I}_{3}{ }^{\mathrm{T}}=\mathrm{I}_{3}{ }^{\mathrm{CG}}-\left(\mathrm{I}_{3}{ }^{\circ}-\mu_{\mathrm{C}}[\mathrm{C}]-\mu_{\mathrm{G}}[\mathrm{G}]\right) \approx \mathrm{I}_{3}{ }^{\mathrm{CG}}-\left(\mathrm{I}_{3}{ }^{\circ}-\mu_{\mathrm{G}}[\mathrm{G}]\right)$, since experimental results have shown that $\mu_{\mathrm{c}} \approx 0$. Then

$$
\mathrm{I}_{3}^{\mathrm{T}}=\mu_{\mathrm{o}} \frac{\mathrm{K}_{\mathrm{C}}[\mathrm{C}][\mathrm{G}]}{1+\mathrm{K}_{\mathrm{C}}[\mathrm{C}]} .
$$

Taking the reciprocals of both sides, thus

$$
\frac{1}{\mathrm{I}_{3}^{\mathrm{T}}}=\frac{1}{\mu_{\mathrm{o}}[\mathrm{G}]}+\frac{1}{\mu_{\mathrm{o}} \mathrm{K}_{\mathrm{c}}[\mathrm{G}][\mathrm{C}]} \text {. }
$$

From the slope and intercept of the plot of $1 / \mathrm{I}_{3}{ }^{\mathrm{T}}$ against $1 /[\mathrm{C}], \mathrm{K}_{\mathrm{C}}$ can be determined by

$$
\mathrm{K}_{\mathrm{C}}=\frac{\text { intercept }}{\text { slope }} \text {. }
$$

\section{Experimental}

The positron source ${ }^{22} \mathrm{Na}$ of about $20 \mu \mathrm{Ci}$ was heat sealed between two $8 \mu \mathrm{m}$ Kapton films $/ 3 /$. The samples used in the experiments were prepared by one of the authors, Daniel W. Armstrong of The University of Missouri-Rolla. A stock solution of known molarity was prepared and then the stock solution was diluted with distilled water to make a solution of the required strength. Positron annihilation lifetime measurements were made with a conventional fast-fast coincidence system with a time resolution of $.303 \mathrm{~ns}$. Lifetime spectra have been obtained in aqueous solutions of different concentrations of nitrophenol isomers, cyclodextrins, and cyclodextrins mixed with a constant concentration of nitrophenol isomers.

\section{Results and Discussion}

Positron annihilation lifetime spectra were resolved into three lifetime components using the program POSITRONFIT-EXTENDED/4/. The lifetime of the first component, corresponding to para-Ps decay, was fixed at .125 ns. The lifetime of the second component, corresponding to freepositron and/or bound-state annihilation, had values $\approx .4 \mathrm{~ns}$. The Lifetime of the third component, corresponding to the pick-off annihilation of ortho-Ps, was around 1.8 to $2 \mathrm{~ns}$.

Positron lifetime spectra were obtained for $\mathrm{m}-\mathrm{NPH}$ and $\mathrm{p}-\mathrm{NPH}$ of concentrations ranging from 0 to around $.06 \mathrm{mM}$. The most significant result was that the intensity $\mathrm{I}_{3}$ decreased linearly with an increase of the concentration of both isomers. Plots of the intensity $I_{3}$ and the annihilation rate $\lambda_{3}$ as a function of p-nitrophenol concentration $\left(\square: I_{3}, \Delta: \lambda_{3}\right)$ are shown in Fig. 1. Since nitrophenol isomers are known to be good electron acceptors, the primary mechanism responsible for the decrease in intensity $\mathrm{I}_{3}$ may be due to competition for electrons in the positron spur. Another effect may be due to the formation of Ps compounds and their subsequent annihilation at a fast decay rate which make them part of the second lifetime component. The inhibition constants $\mu_{\mathrm{G}}$ were determined for both isomers using a linear least-squares fit of the data.

Positron lifetime spectra were measured for aqueous solutions of $\alpha^{-}, \beta^{-}$, and $\gamma$-cyclodextrins. Concentrations ranged from 0 to $.144 \mathrm{M}$ for $\alpha-C D$, from 0 to $.0163 \mathrm{M}$ for $\beta-C D$, and from 0 to $.18 \mathrm{M}$ for $\gamma$-CD. $\beta$-CD has a very low solubility while $\gamma-C D$ has the greatest solubility in water. All three cyclodextrins exhibited a slight decrease in the intensity $I_{3}$ with an increase in concentration. Fig. 1 shows plots of the intensity $I_{3}$ and the annihilation rate $\lambda_{3}$ as a function of 
$\alpha$-cyclodextrin concentration $\left(x: I_{3},+: \lambda_{3}\right)$. Cyclodextrins appeared to be less effective as electron acceptors than nitrophenols based on these results. The inhibition constants $\mu_{\mathrm{c}}$ for cyclodextrins were very nearly zero. Values of $\mu_{\mathrm{G}}$ and $\mu_{\mathrm{C}}$ are listed in Table 1.

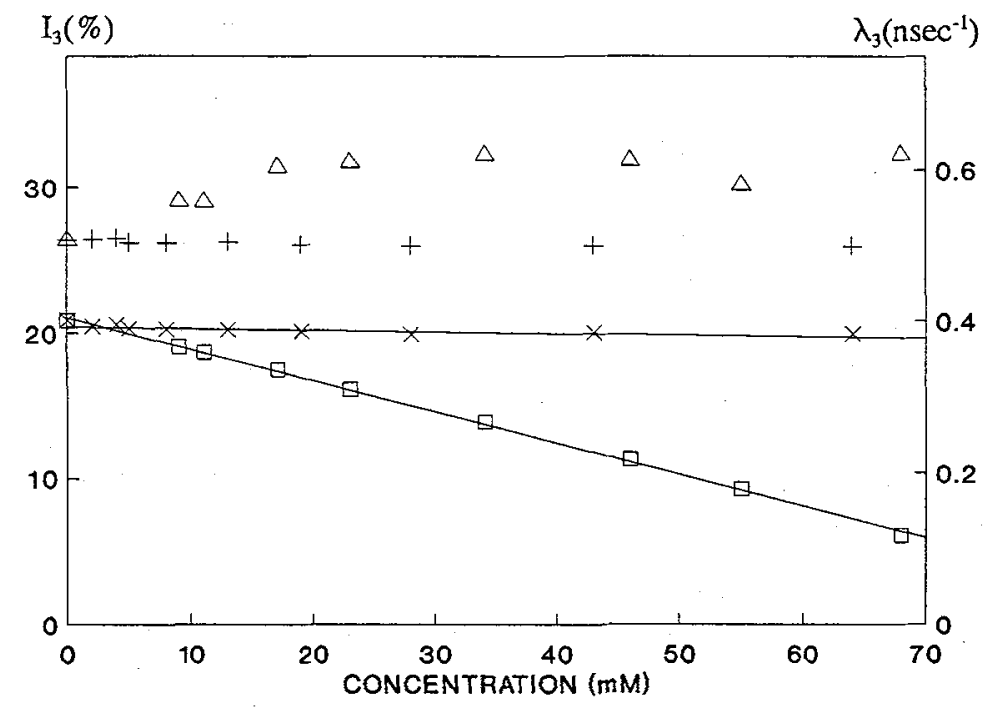

Fig. 1 The intensity $I_{3}$ and the annihilation rate $\lambda_{3}$ as a function of concentration in an aqueous solution of $\alpha$-cyclodextrin $\left(x: I_{3},+: \lambda_{3}\right)$ and p-nitrophenol $\left(\square: I_{3}, \Delta: \lambda_{3}\right)$.

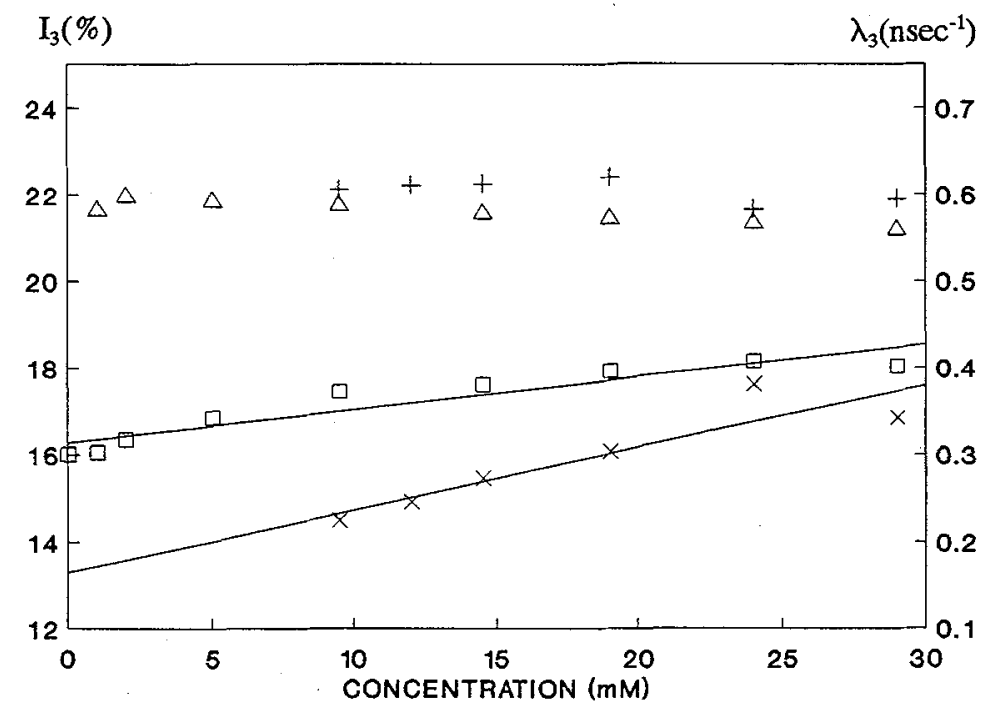

Fig. 2 The intensity $I_{3}$ and the annihilation rate $\lambda_{3}$ as a function of concentration of $\alpha$ cyclodextrin in an aqueous solution with a fixed concentration of $p$-nitrophenol $\left(\times: I_{3},+: \lambda_{3}\right.$ for $35.6 \mathrm{mM}$ of $\mathrm{p}-\mathrm{NPH} ; \square: \mathrm{I}_{3}, \Delta: \lambda_{3}$ for $23.1 \mathrm{mM}$ of $\left.\mathrm{p}-\mathrm{NPH}\right)$. 
Table 1: Inhibition constants $\mu$

\begin{tabular}{cr}
\hline Solute & \multicolumn{1}{c}{$\mu\left(\mathrm{M}^{-1}\right)$} \\
\hline m-nitrophenol & $195.1 \pm 1.47$ \\
p-nitrophenol & $208.5 \pm 1.32$ \\
$\alpha$-cyclodextrin & $5.45 \pm 0.78$ \\
$\beta$-cyclodextrin & $4.32 \pm 8.75$ \\
$\gamma$-cyclodextrin & $3.04 \pm 1.55$ \\
\hline
\end{tabular}

The effects of cyclodextrins on positron lifetime spectra in an aqueous solution with a constant molarity of nitrophenol isomers were examined for three cyclodextrins. In all cases the most important result was an increase in the intensity $\mathrm{I}_{3}$ of the third component with an increase in $\mathrm{CD}$ concentration, in contrast with a decrease in $\mathrm{I}_{3}$ in an aqueous solution of a single solute. The effect can be seen in Fig 2. The graph plots the intensity $I_{3}$ and the annihilation rate $\lambda_{3}$ as a function of concentration of $\alpha$-cyclodextrin in an aqueous solution with a fixed concentration of $p-N P H\left(x: I_{3}\right.$, $+: \lambda_{3}$ for $35.6 \mathrm{mM}$ of $\mathrm{p}-\mathrm{NPH} ; \square: \mathrm{I}_{3}, \Delta: \lambda_{3}$ for $23.1 \mathrm{mM}$ of $\mathrm{p}-\mathrm{NPH}$ ). It clearly indicates that as $\mathrm{p}-$ nitrophenol is complexed, it becomes less effective as an electron acceptor; the inhibition effect is therefore reduced. Since the intensity $I_{3}$ exhibited a linear behavior in the low cyclodextrin concentration region, the proposed methods (1) and (2) for determination of the equilibrium constants $\mathrm{K}_{\mathrm{C}}$ have been used. Fig. 3 plots $1 / \mathrm{I}_{3}{ }^{\mathrm{T}}$ as a function of $1 /[\mathrm{C}] .[\mathrm{C}]$ is the concentration of $\alpha$-cyclodextrin in an aqueous solution with a fixed concentration of p-nitrophenol ( $a$ for $35.6 \mathrm{mM}$ of $\mathrm{p}-\mathrm{NPH}$; $\Delta$ for $23.1 \mathrm{mM}$ of p-NPH). From these data the proposed method (3) was used to determine $\mathrm{K}_{\mathrm{C}}$. Values of $\mathrm{K}_{\mathrm{C}}$ are listed in Table 2.

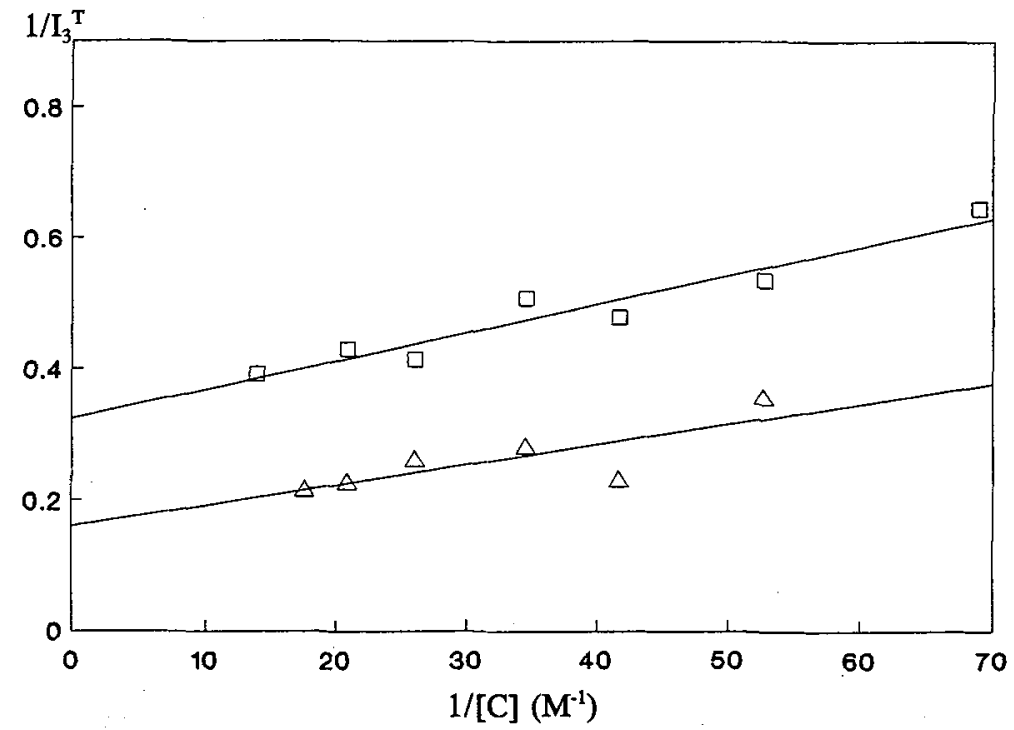

Fig. 3 Plots of $1 / \mathrm{I}_{3}{ }^{\mathrm{T}}$ as a function of $1 /[\mathrm{C}]$. [C] is the concentration of $\alpha$-cyclodextrin in an aqueous solution with a fixed concentration of p-nitrophenol. ( $\square$ for $35.6 \mathrm{mM}$ of $\mathrm{p}-\mathrm{NPH} ; \Delta$ for $23.1 \mathrm{mM}$ of $\mathrm{p}-\mathrm{NPH}$ ). 
Table 2 : Complex formation equilibrium constants $K_{c}\left(M^{-1}\right)$

\begin{tabular}{llcrrr}
\hline $\mathrm{CD}$ & $\mathrm{NPH}$ & \multicolumn{1}{c}{$\mathrm{K}_{\mathrm{c}}{ }^{2}$} & \multicolumn{1}{c}{$\mathrm{K}_{\mathrm{C}}{ }^{\mathrm{b}}$} & \multicolumn{1}{c}{$\mathrm{K}_{\mathrm{c}}{ }^{\mathrm{c}}$} & \multicolumn{1}{c}{$\mathrm{K}_{\mathrm{C}}{ }^{\mathrm{d}}$} \\
\hline$\alpha-\mathrm{CD}$ & $\mathrm{p}-\mathrm{NPH}(1)$ & \multirow{2}{*}{$15 \pm 16$} & $31 \pm 4$ & $63 \pm 1$ & $220 \pm 20$ \\
$\alpha-\mathrm{CD}$ & $\mathrm{p}-\mathrm{NPH}(2)$ & & $27 \pm 3$ & $46 \pm 1$ & \\
$\alpha-\mathrm{CD}$ & $\mathrm{m}-\mathrm{NPH}(1)$ & $73 \pm 150$ & $7 \pm 2$ & $318 \pm 14$ & $124 \pm 5$ \\
$\alpha-\mathrm{CD}$ & $\mathrm{m}-\mathrm{NPH}(2)$ & & $5 \pm 1$ & $256 \pm 12$ & \\
$\beta-\mathrm{CD}$ & $\mathrm{p}-\mathrm{NPH}(3)$ & $373 \pm 420$ & $134 \pm 34$ & $197 \pm 1$ & $350 \pm 50$ \\
$\beta-\mathrm{CD}$ & $\mathrm{p}-\mathrm{NPH}(4)$ & & $131 \pm 83$ & $265 \pm 1$ & \\
$\gamma-\mathrm{CD}$ & $\mathrm{p}-\mathrm{NPH}(5)$ & & & & \\
$\gamma-\mathrm{CD}$ & $\mathrm{p}-\mathrm{NPH}(6)$ & $90 \pm 33$ & $40 \pm 10$ & & \\
\hline
\end{tabular}

$\mathrm{K}_{\mathrm{C}}{ }^{\mathrm{a}}$ : calculated using method (1); $\mathrm{K}_{\mathrm{C}}{ }^{\mathrm{b}}$ : calculated using method (2); $\mathrm{K}_{\mathrm{C}}{ }^{\mathrm{c}}$ : calculated using method (3); and $\mathrm{K}_{\mathrm{C}}{ }^{\mathrm{d}}$ : measured from other studies $/ 5 /$.

$\mathrm{p}-\mathrm{NPH}(\star): \star=1: 23.1 \mathrm{mM} ; 2: 35.6 \mathrm{mM} ; 3: 7.2 \mathrm{mM} ; 4: 23.1 \mathrm{mM} ; 5: 28.1 \mathrm{mM} ; 6: 42.2 \mathrm{mM}$. $\mathrm{m}-\mathrm{NPH}(\star): \star=1: 11.6 \mathrm{mM} ; 2: 24.6 \mathrm{mM}$.

In conclusion, the present experimental results showed that nitrophenol is a good Ps inhibitor. The intensity of the third lifetime component, $I_{3}$, which is due to the pick-off annihilation of ortho-Ps, is reduced. As cyclodextrin is added to the solution, nitrophenol molecules form inclusion complexes with cyclodextrin molecules, the inhibition effect is thus reduced, resulting in a subsequent increase of the intensity $I_{3}$ of the third lifetime component. Based on these findings, three methods are proposed to determine the complex formation equilibrium constants. Although present results could not conclusively show which method gave the best result, the technique appears to be promising. More data are required in order to get a more reliable determination of these constants using the positron annihilation technique.

\section{References}

11/ For general references, see (a) Bender, M. L. and Komiyama, M. : Cyclodextrin Chemistry, Springer-Verlag, Berlin / Heidelberg / New York, 1978; (b) Szejtli, J. : Cyclodextrin Technology, Kluwer Academic Publishers, Dordrecht / Boston / London, 1988.

12/ Jean, Y. C, and Ache, H. J., J. Phys. Chem. 81 (1977) 2093.

13/ Zhou, G. M., Sung, S., Sundar, C. S., Mahmood, T., and Jean, Y. C., in Positron and Positronium Chemistry, edited by Jean, Y. C., ( World Scientific, Singapore / New Jersey / London / Hong Kong, 1990) P. 180.

14/ Kirkegaard, P. and Eldrup, M. Comp. Phys. Comm. 7 (1974) 401.

15/ Bertrand, G. L., Faulker, J. R. Jr., Han, S. M., and Armstrong, D. W., J. Phys. Chem. 93 (1989) 6863. 